Int. J. Dev. Biol. 58: 851-861 (2014)

doi: $10.1387 / \mathrm{ijdb} .140207 \mathrm{ml}$

\title{
Optogenetics in Developmental Biology: using light to control ion flux-dependent signals in Xenopus embryos
}

\author{
DANY SPENCER ADAMS ${ }^{1}$, JOAN M. LEMIRE', RICHARD H. KRAMER ${ }^{2}$ and MICHAEL LEVIN*,1 \\ ${ }^{1}$ Dept of Biology and Center for Regenerative and Developmental Biology, Tufts University, Medford, MA and \\ ${ }^{2}$ Dept of Molecular and Cell Biology, University of California, Berkeley, CA, USA
}

\begin{abstract}
Developmental bioelectricity, electrical signaling among non-excitable cells, is now known to regulate proliferation, apoptosis, gene expression, and patterning during development. The extraordinary temporal and spatial resolution offered by optogenetics could revolutionize the study of bioelectricity the same way it has revolutionized neuroscience. There is, however, no guide to adapting optogenetics to patterning systems. To fill this gap, we used optogenetic reagents, both proteins and photochemical switches, to vary steady-state bioelectrical properties of non-spiking embryonic cells in Xenopus laevis. We injected mRNA for various proteins, including Channelrhodopsins and Archaerhodopsin, into 1-8 cell embryos, or soaked embryos in media containing photochemical switches, then examined the effect of light and dark on membrane voltage $\left(V_{\text {mem }}\right)$ using both electrodes and fluorescent membrane voltage reporters. We also scored tadpoles for known effects of varying $V_{\text {mem }}$, including left-right asymmetry disruption, hyperpigmentation, and craniofacial phenotypes. The majority of reagents we tested caused a significant increase in the percentage of light-exposed tadpoles showing relevant phenotypes; however, the majority of reagents also induced phenotypes in controls kept in the dark. Experiments on this "dark phenotype" yielded evidence that the direction of ion flux via common optogenetic reagents may be reversed, or unpredictable in non-neural cells. When used in combination with rigorous controls, optogenetics can be a powerful tool for investigating ion-flux based signaling in non-excitable systems. Nonetheless, it is crucial that new reagents be designed with these non-neural cell types in mind.
\end{abstract}

KEY WORDS: optogenetics, photochemical switch, bioelectricity, Xenopus, embryo

\section{Introduction}

Changes in resting potential control cell migration, differentiation, and proliferation (McCaig et al., 2009, Sundelacruz et al., 2009), including the regulation of stem/progenitor cell differentiation (Hinard et al., 2008, Lange et al., 2011, Sundelacruz et al., 2008) and tumor growth (Chernet and Levin, 2013, Chernet and Levin, 2014, Lobikin et al., 2012, Yang and Brackenbury, 2013). Crucially, spatio-temporal gradients of resting potential $\left(\mathrm{V}_{\mathrm{mem}}\right)$ act as bioelectrical signals that serve as instructive mediators of patterning information during embryogenesis, regeneration, and cancer (Adams, 2008, Levin, 2012). Recently-developed molecular techniques to alter $V_{\text {mem }}$ have shown great promise for probing the mechanisms of large-scale pattern formation and the control of biological growth and form during craniofacial development (Vandenberg et al., 2011b), appendage regeneration (Adams et al., 2007, Reid et al., 2009, Tseng et al., 2010), eye development
(Pai et al., 2012), head-tail regenerative polarity (Beane et al., 2011), and left-right axis formation (Adams et al., 2006, Levin et al., 2002). However, these genetic and pharmacological strategies have significant limitations (Adams and Levin, 2013b). Elucidating the bioelectric code (the mapping of physiological properties to future tissue states) (Levin, 2014, Tseng and Levin, 2013), as

\footnotetext{
Abbreviations used in this paper: AAQ, Acrylamide - Azobenzene - Quaternary ammonium; Arch, Archaerhodopsin; CC2-DMPE, N-[6-chloro-7-hydroxycoumarin3-carbonyl] dimyristoyl phosphatidyl ethanolamine; ChR, Channelrhodopsin; Ctrl, control, untreated; $\operatorname{DiBAC}_{4}(3)$, bis-[1,3-dibutylbarbituric acid]trimethine oxonol; Exp, experimental, treated; GHK, Goldman Hodgkin Katz; LiGluR, lightsensitive ionotropic glutamate-receptor; $\lambda_{\max }$, wavelength of maximum activation; MAG, Maleimide-Azobenzene-Glutamate; PCS, photochemical switch; PMA1.2, yeast proton pump; QAQ, Quaternary ammonium - Azobenzene - Quaternary ammonium; Vcomet, C. reinhardtii ChR1 - Volvox ChR1 - ChR2 chimera; $\mathrm{V}_{\text {mem }}$ membrane voltage, resting potential.
}

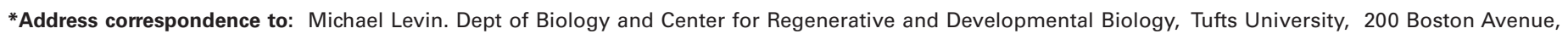
Medford, MA 02155, USA.Tel: +1-(617)-627-6161. Fax: +1-(617)-627-5035. E-mail: Michael.Levin@tufts.edu 
well as developing bioengineering applications for regenerative medicine based on this powerful set of pathways, depends on the ability to control $\mathrm{V}_{\text {mem }}$ in vivo, with tight spatio-temporal specificity.

Optogenetics technology (Miesenbock, 2011) offers exciting prospects for flexible control of $\mathrm{V}_{\text {mem }}$ (voltage potential). Opto- refers to the fact that these reagents can be turned on and/or off by light, -genetic refers to the fact that the first reagents were genetically encoded (Fenno et al., 2011, Knopfel et al., 2010, Miesenbock and Kevrekidis, 2005). The genes encoding these first reagents were taken from protists, for example Chlamydomonas, and encoded light activated channels, such as rhodopsin; the function plus the identity gave rise to the name channel rhodopsin, $\mathrm{ChR}$, a cation channel that is opened by blue light. Subsequent molecular ma-



nipulations of protein sequence, discovery of new light-activated channels, ion pumps, and enzymes, and the synthesis of photochemical switches, small molecules that can act as exogenous, light gated, channel blockers, have all increased the diversity in the optogenetics toolbox. The great advance that these reagents make possible is the ability to activate and de-activate proteins with exquisitely fine control, simply by turning on and off light at the time and place of interest. As of the time of this writing, they have been used almost exclusively to control action potentials in excitable cells (Akerboom et al., 2013, Bernstein et al., 2012, Sakar et al., 2012, Yizhar et al., 2011), including both neurons and muscle, and more and more researchers are using the phrase "optogenetics revolution" to describe the magnitude of the impact this new set tools has had on, for example, neuroscience.

Despite the obvious utility of gaining high-precision temporal and spatial control over protein activity, the application of optogenetics techniques to cells in developmental contexts has only just begun (Adams et al., 2013). Common optogenetic reagents (Welberg, 2013) are currently optimized for extremely rapid and transient activation or suppression of action potential firing in individual cells. Moreover, while optogenetic reagents that stay active for minutes or longer are available (Berndt et al., 2009), their use for the control of steady-state potential gradients in large cell fields is also just beginning to be studied. Our goal was to adapt the strategies of optogenetics for studies of ion-dependent signaling roles during patterning and morphogenesis.

The advantages of Xenopus laevis for studies of developmental, regenerative, and neoplastic processes are numerous. Large numbers of embryos are available; moreover, the large size of the early cells (the fertilized egg is over $1 \mathrm{~mm}$ in diameter) facilitates microinjection. A plethora of molecular-genetic tools are available in this model (Koide et al., 2005). A unique situation for Xenopus is that its oocytes are the system of choice for testing the activity of introduced proteins, especially ion channels (Crane and Ruderman, 2006). Finally, there is a growing collection of data on the importance of ion-flux-dependent signaling during development and regeneration in Xenopus, such as patterning of the left-right axis (Adams et al., 2006), appendage regeneration (Adams et al., 2007), and craniofacial development (Vandenberg et al., 2011a). Moreover, we have already performed analyses of markers that show the correspondence between expression of developmentally important genes, bioelectrical signals, and the resulting phenotypes (Vandenberg et al., 2011b). The ability to target molecular reagents, such as morpholinos or mutant mRNA, to specific organs in this organism is aided by the detailed fate

Fig. 1. Expression of optogenetic reagents in Xenopus embryos at different ages. Embryos in A to Hare $1.2 \mathrm{~mm}$ in diameter. (A-F) mRNA for constructs was injected at the one or two cell stage. A to $F$ are taken from a time lapse movie of an embryo that had been injected with LiGluR-tom. By monitoring tomato fluorescence we can see that the protein begins to accumulate at the cell surface by 85 minutes post-injection (B) and within another 10 to 15 minutes (C,D), it's expression is quite strong. It is also clear that the bolus does not diffuse far from the injection site, thus in this embryo, only one cell is positive for the protein (E) until almost four hours post injection (F). Embryos continue to express the proteins through late gastrula stages $(\mathbf{G}, \mathbf{H})$, here illustrated by the expression of Vcomet-HRDAtom in all the cells that also contain lineage tracer to follow those cells that received the MRNA. Protein is also still clearly visible in cells, over 7 days after injection (I) illustrated here by expression of ChR2-C128T-GFP in skin cells of a tadpole. 
TABLE 1

\section{OPTOGENETICS REAGENTS USED}

\begin{tabular}{|c|c|c|c|c|c|c|}
\hline mRNA & Details (amino acid \#) & $\lambda_{\text {act }}$ & $\lambda_{\text {inh }}$ & $\begin{array}{l}\text { Required Irradiance } \\
{\left[\mathrm{mW} / \mathrm{mm}^{2}\right]}\end{array}$ & $\begin{array}{l}\text { Off rate constant } \\
\text { On-Off Light Regimen }\end{array}$ & Ref \\
\hline GFP-Arch; Arch & aop3 $^{\dagger}$ & 580 & & $\approx 1$ (assumed) & $\begin{array}{l}500 \mathrm{~ms} \\
500 \mathrm{~ms}-2 \mathrm{~s}\end{array}$ & (Chow et al., 2010) \\
\hline GFP-ChR2-C128T & $\mathrm{COP}^{\mathrm{D}}(1-309) ; \mathrm{C} 128 \mathrm{~T}$ & 450 & 546 & 0.24 & $\begin{array}{l}2 \mathrm{~s} \\
10 \mathrm{~ms}-2 \mathrm{~s}\end{array}$ & (Berndt et al., 2009, Kleinlogel et al., 2011) \\
\hline GFP-ChR2-C128T-NRB ${ }^{\mathrm{n}}$ & $\mathrm{COP}^{\mathrm{b}}$ (1-309); C128T K287S & 450 & 546 & 0.24 & $\begin{array}{l}? \\
10 \mathrm{~ms}-2 \mathrm{~s}\end{array}$ & (Nagel et al., 2005) \\
\hline GFP-ChR2-D156A & $\mathrm{COP}^{\mathrm{a}}{ }^{(1-309) ; D 156 A}$ & 450 & 546 & 2.4 & $\begin{array}{l}30 \\
10 \mathrm{~ms}-30 \mathrm{~s}\end{array}$ & (Bamann et al., 2010) \\
\hline GFP-Melan-opsin & Opn4, transcript variant 1 , mouse. & 540 & & & & (Melyan et al., 2005; (Koizumi et al., 2013) \\
\hline Tom-PMA1.2 & $\begin{array}{l}\text { PMA1 } \mathrm{H}^{+} \text {-exporting P2-type ATPase [S. cerevisiae S288c]; } \\
\text { tdTomato. }\end{array}$ & $\mathrm{N} / \mathrm{A}$ & & $\mathrm{N} / \mathrm{A}$ & $\mathrm{N} / \mathrm{A}$ & (Adams et al., 2013) \\
\hline Tom-Vcomet-HRDA & $\begin{array}{l}\operatorname{COP}^{\mathrm{c}}(1-95), \\
\operatorname{VchR}^{\mathrm{d}}(151-201), \mathrm{VchR}^{\mathrm{e}}(202-233), \mathrm{VchR}^{\mathrm{d}}(234-300) \\
H 129 R, D 151 A\end{array}$ & 630 & & $\approx 1$ (assumed) & $\begin{array}{l}1.6 \\
500 \mathrm{~ms}-3 \mathrm{~s}\end{array}$ & (Lin, JY, pers comm) \\
\hline Tom-Vcomet-HRFY & 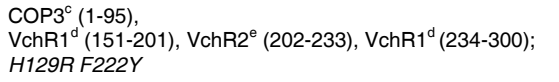 & 630 & & $\approx 1$ (assumed) & $\begin{array}{l}5 \\
1 s-5 s\end{array}$ & (Lin, JY pers comm) \\
\hline \multicolumn{5}{|l|}{ Photochemical Switches } & Conc $[\mu \mathrm{M}]$ & \\
\hline$\overline{A A Q}$ & Acrylamide-Azobenzene-Quaternary ammonium & 500 & 380 & $3.5,0.5$ & $\begin{array}{l}400 \\
1 \mathrm{~s}-60 \mathrm{~s}\end{array}$ & (Polosukhina et al., 2012) \\
\hline MAG + LiGluR ${ }^{g}$ & $\begin{array}{l}\text { Maleimide-Azobenzene-Glutamate } 1+ \\
\text { Light-sensitive Ionotropic Glutamate Receptor (L439C) }\end{array}$ & 380 & 500 & 0.012 & $\begin{array}{l}100 \\
1 \mathrm{~s}-60 \mathrm{~s}\end{array}$ & (Volgraf et al., 2006) \\
\hline QAQ & $\begin{array}{l}\text { Quaternary ammonium - Azobenzene-Quaternary } \\
\text { ammonium }\end{array}$ & 500 & 380 & $3.5,0.5$ & $\begin{array}{l}400 \\
1 \mathrm{~s}-60 \mathrm{~s}\end{array}$ & (Mourot et al., 2012) \\
\hline
\end{tabular}

map that predicts future cell identity, and by the ease with which these reagents can be microinjected into the large cells of the early embryo, or electroporated into the cells of older embryos. These techniques, however, lack both the spatial and temporal resolution afforded by light activated proteins. To add optogenetics to the toolkit available for this important system would greatly accelerate important advances.

Adapting the rhodopsins, photochemical switches (PCS), etc., for use in models such as the developing Xenopus involves dealing with the enormous differences between mammalian neurons and the cells of these embryos, as well as the difference between working with a single, differentiated cell and a constantly changing multicellular organism. However, the rewards of success would be tremendous. Identification, by stimulation or inhibition, of the exact cell type and physiological state responsible for bioelectrically triggering major events of differentiation or morphogenesis, would yield unprecedented insight into mechanisms of developmental control, insight that could have profound effects on drug development, our understanding of stem cell biology, evolutionary biology, regenerative bioengineering, and prevention of birth defects. Moreover, the ability to define and modulate the patterns of isopotential regions of cell populations would significantly expand the toolkit of synthetic biology. Thus, we have begun to determine how to deploy optogenetics for developmental research in Xenopus.

\section{Results}

Prediction of optogenetic reagent function in frog blastomeres

We report here on our experiments with in vivo expression and manipulation of ten optogenetic reagents in developing Xenopus embryos (listed in Table 1). Table 2 summarizes the predicted ef- fects of those reagents based on the reported effects in neurons and the Goldman-Hodgkin-Katz (GHK) equation. It is important to remember that the Xenopus embryo is opaque, thus light cannot penetrate below the outermost, or ectodermal, layer of cells. The cells that will become placodes (which give rise to eyes, otic capsules, and olfactory bulbs) and the cells that will become neural crest (those that give rise to the jaws and branchial arches) are part of the ectoderm covering the dorsal surface of the embryo during the stages studied. These outermost cells, that contribute so much of the face, are in contact with fresh-water-like medium, not extracellular fluid, thus the concentration gradients of the

TABLE 2

\section{COMPARISON OF OPTOGENETIC-REAGENTS OBSERVED EFFECTS ON NEURONS AND PREDICTED EFFECTS ON BLASTOMERES}

\begin{tabular}{|c|c|c|c|c|}
\hline \multirow[b]{2}{*}{$\begin{array}{l}\text { AAQ } \\
\text { (in trans, in the dark) }\end{array}$} & \multicolumn{2}{|c|}{ Observed in neurons } & \multicolumn{2}{|c|}{ Predicted in blastomeres } \\
\hline & $\mathrm{D}$ & V-gated $\mathrm{K}^{+}$efflux blocked & $\mathrm{D}$ & V-gated $\mathrm{K}^{+}$efflux blocked \\
\hline $\begin{array}{l}\text { Arch } \\
\mathrm{H}^{+} \text {pump }\end{array}$ & $\mathrm{H}$ & $\mathrm{H}^{+}$efflux & $\mathrm{H}$ & $\mathrm{H}^{+}$efflux \\
\hline $\begin{array}{l}\text { ChR2 } \\
\text { Cation channels }\end{array}$ & $\mathrm{D}$ & Net cation influx & $\mathrm{H}$ & Cation efflux \\
\hline $\begin{array}{l}\text { LiGluR + MAG1 } \\
\text { Cation channel }\end{array}$ & $\mathrm{D}$ & Net cation influx & $\mathrm{H}$ & Cation efflux \\
\hline $\begin{array}{l}\text { Melanopsin } \\
\text { G-protein }\end{array}$ & $\mathrm{H}$ & $\begin{array}{l}\text { Net } \mathrm{Na}^{+} \text {influx plus } \mathrm{Ca}^{2+} \text {-store } \\
\text { release via coupling to TRPC }\end{array}$ & $\mathrm{H}$ & $\begin{array}{l}\mathrm{Na}^{+} \text {and } \mathrm{K}^{+} \text {efflux, unknown } \\
\text { effect on } \mathrm{Ca}^{2+}\end{array}$ \\
\hline $\begin{array}{l}\text { QAQ } \\
\text { (in trans, in the dark) }\end{array}$ & $\mathrm{D}$ & V-gated ion channels blocked & $\mathrm{D}$ & Cation efflux blocked \\
\hline $\begin{array}{l}\text { Vcomet } \\
\text { Cation Channels }\end{array}$ & $\mathrm{D}$ & Net cation influx & $\mathrm{H}$ & Cation efflux \\
\hline
\end{tabular}

The Goldman-Hodgkin-Katz equation was used to predict the direction of ion-flux for each reagent based on published values of ion concentrations and permeability coefficients. $\mathrm{H}=$ hyperpolarization, $\mathrm{D}=$ depolarization. 


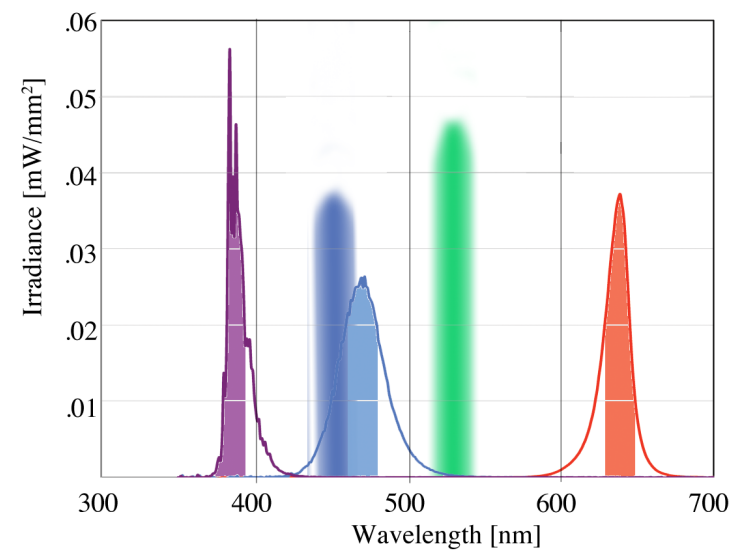

\begin{tabular}{|c|c|c|c|c|}
\hline Illuminator & Color & $\boldsymbol{\lambda} \mathbf{m a x}$ & $\mathbf{m W} / \mathbf{m m}^{2}$ & height \\
\hline LED & Violet & $384 \mathrm{~nm}$ & 0.48 & $2^{\prime \prime}$ \\
\hline Cube & Blue & $463 \mathrm{~nm}$ & 0.77 & 2.3 \\
\hline LED & Blue & $471 \mathrm{~nm}$ & 0.47 & $2^{\prime \prime}$ \\
\hline Cube & Green & $523 \mathrm{~nm}$ & 0.96 & $2.3 "$ \\
\hline LED & Red & $639 \mathrm{~nm}$ & 0.56 & $2^{\prime \prime}$ \\
\hline
\end{tabular}

Fig. 2. Power spectra of illuminators used to activate or de-activate channels. Two types of illumination systems were used, LED arrays and fiberoptically delivered LED lights inside light-tight cubes. Arrays comprised six LEDs arranged in a circle and aimed towards a central point. Irradiance inside the cubes was measured by the manufacturer at $\lambda$ max. Irradiance of the LED arrays was measured using a USB650 spectrometer, an LS1-CAL lamp for calibration, and SpectraSuite software. As much as possible given the difference in thicknesses, the sensor was placed at the same distance from the light as the embryos, as indicated in the table. To calculate irradiance, each curve was integrated from $\lambda_{\max }-10 \mathrm{~nm}$ through $\lambda_{\max }+10 \mathrm{~nm}$.

ions all favor efflux. Predictions using the GHK equation are consistent with that expectation; Table 2 compares these predictions with published observations in neurons. Because the medium in which the tadpoles develop is so dilute, almost all of the reagents we tried are predicted to hyperpolarize, including the ChR2s. Only the $P C S s A A Q$ and $Q A Q$ were predicted to depolarize the cells on the surface of the embryo.

\section{Optogenetic reagents cloned into the pCS2+ vector are ex- pressed}

The first test of the utility of available optogenetics reagents was to determine whether Xenopus embryonic cells would express each protein. Every optogenetic construct we tested was indeed translated and the fused marker red fluorescent protein tdTomato was detected at the surface of cells. Moreover, protein was expressed within a couple of hours of mRNA injection (Fig. 1; see also Adams et al., 2013).

\section{Control experiments show that most light wavelengths have no effect on Xenopus development}

It was important to determine whether the relevant wavelengths (Fig. 2) directly affected Xenopus embryos, since a number of native photo-sensitive pathways have been discovered outside of the visual system in this and other systems (Ward et al., 2008). Except for embryos younger than the 16 cell stage that were adversely affected by $380 \mathrm{~nm}$ light, none of the lighting protocols influenced development of untreated embryos as long as the temperature was maintained below $24^{\circ} \mathrm{C}$.

\section{Controlexperiments show that fluorescent proteins conjugated to optogenetic reagents do not affect the results}

Because optogenetics involves light-activation of proteins, we wanted to learn whether light interacting with fluorescent proteins would confound our results. We therefor constructed two versions of ChR2-C128T, one with tomato and one with no fluorescent protein, and three versions of Arch, one with tomato, one with GFP, and one with no fluorescent protein. We found no evidence indicating that fluorescent proteins alter the results of expressing Arch or Chr2-C128T (data not shown).

\section{Resting potential is altered by optogenetics reagents}

We confirmed activity of the reagents by measuring $\mathrm{V}_{\text {mem }}$. We used two methods for measuring $\mathrm{V}_{\text {mem }}$, electrodes (on larger early cells) and voltage reporter dyes (on smaller, tomato-expressing later cells). First, traditional electrophysiological impalement was used to compare average membrane potentials of the large cells in embryos with between 1 and 4 cells. Because the tomato-fluorescence that confirms expression of injected mRNAs is not visible until late in the 4-cell stage, and because expression is not present in every cell (Fig. $1 \mathrm{C}, \mathrm{D})$, we used AAQ-exposed embryos for these measurements. The results are shown in Figure 3. The measurements of untreated cells match published reports, and are consistent with the gradual increase in polarization of the early cells, a.k.a. blastomeres. We also performed a positive control on the measuring apparatus by monitoring the effect of depolarizing solution. However, from the 2-cell stage to at least the 8-cell stage, AAQ-treated blastomeres were hyperpolarized relative to untreated blastomeres. This is different from either predicted effect of $A A Q$, which, under the lighting conditions present, should be in the trans conformation and therefore blocking endogenous potassium-channel targets, which should cause depolarization, or have no effect. Instead, these data suggest that while $A A Q$ is active and affects bioelectrical characteristics of

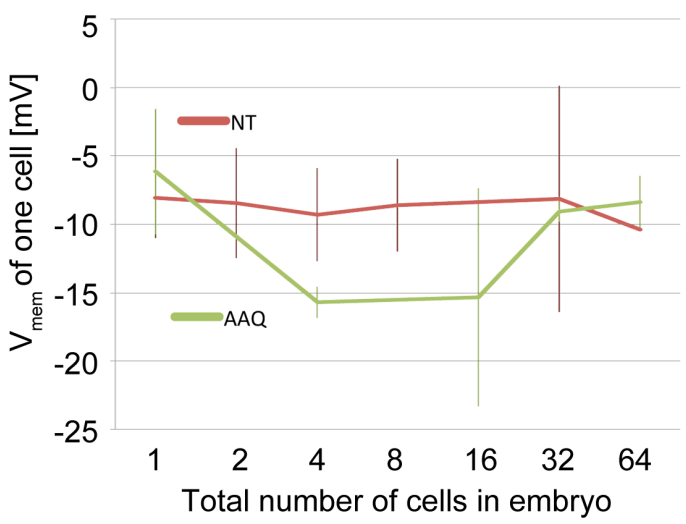

Fig. 3. $\mathbf{V}_{\text {mem }}$ of early Xenopus embryo cells (blastomeres) treated with AAQ. Resting potential of individual cells was measured using microelectrodes. Uncertainty bars are standard deviations. The measurement of untreated embryos match published values, and addition of a depolarizing solution caused the measurement to change appropriately (data not shown). In contrast, embryos that had been exposed to $A A Q$ for 20 minutes prior to measurement were hyperpolarized relative to the untreated controls at some stages. These results are opposite our prediction of depolarization. 
TABLE 3

\section{EFFECT OF ACTIVATING WAVELENGTH ON PROPORTION OF TADPOLES SHOWING PHENOTYPES}

A

\begin{tabular}{|c|c|c|c|c|c|c|}
\hline \multirow[b]{3}{*}{ mRNA or PCS } & \multicolumn{6}{|c|}{ Active vs NT (Predicted: $p<0.01$ ) } \\
\hline & \multicolumn{2}{|c|}{ Active } & \multicolumn{2}{|c|}{ NT } & \multirow[b]{2}{*}{$\chi^{2}$} & \multirow[b]{2}{*}{$\mathbf{p}$} \\
\hline & $\mathbf{n}$ & $\%$ & $\mathbf{n}$ & $\%$ & & \\
\hline $\mathrm{AAQ}$ & 228 & 36 & 341 & 15 & 32.6 & $<0.001$ \\
\hline Arch & 103 & 50 & 591 & 12 & $>50.0$ & $<0.001$ \\
\hline Arch + PMA & 60 & 28 & 591 & 12 & 13.2 & $<0.001$ \\
\hline Chr2-C128T & 217 & 60 & 1031 & 14 & $>200$ & $<0.001$ \\
\hline Chr2-D156A & 111 & 45 & 369 & 16 & 41.0 & $<0.001$ \\
\hline LiGluR + MAG1 & 104 & 28 & 317 & 14 & 11.3 & 0.001 \\
\hline Melanopsin & 154 & 21 & 404 & 7 & 24.1 & $<0.001$ \\
\hline Vcomet-HRDA & 159 & 39 & 442 & 12 & 57.7 & $<0.001$ \\
\hline Vcomet-HRFY & 18 & 61 & 365 & 13 & 31.1 & $<0.001$ \\
\hline
\end{tabular}

\begin{tabular}{|c|c|c|c|c|c|c|}
\hline \multirow{3}{*}{$\begin{array}{l}\text { B } \\
\text { mRNA or PCS }\end{array}$} & \multicolumn{6}{|c|}{ Active vs Inactive (Predicted: $p<0.01$ ) } \\
\hline & \multicolumn{2}{|c|}{ Active } & \multicolumn{2}{|c|}{ Inactive } & \multirow[b]{2}{*}{$\chi^{2}$} & \multirow[b]{2}{*}{$\mathbf{p}$} \\
\hline & $\mathbf{n}$ & $\%$ & $\mathbf{n}$ & $\%$ & & \\
\hline AAQ & 228 & 36 & 196 & 9 & 41.2 & $<0.001$ \\
\hline LiGluR + MAG1 & 104 & 28 & 54 & 17 & 2.45 & 0.118 \\
\hline Vcomet-HRFY & 18 & 61 & 78 & 37 & 3.5 & 0.063 \\
\hline
\end{tabular}

\begin{tabular}{|c|c|c|c|c|c|c|}
\hline \multirow[b]{3}{*}{ mRNA or PCS } & \multicolumn{6}{|c|}{ Active vs Dark (Predicted: $p<0.01$ ) } \\
\hline & \multicolumn{2}{|c|}{ Active } & \multicolumn{2}{|c|}{ Dark } & \multirow[b]{2}{*}{$\chi^{2}$} & \multirow[b]{2}{*}{$\mathbf{p}$} \\
\hline & $\mathbf{n}$ & $\%$ & $\mathbf{n}$ & $\%$ & & \\
\hline Arch GFP & 103 & 50 & 168 & 45 & 4.2 & 0.041 \\
\hline Arch + PMA & 60 & 28 & 50 & 10 & 5.7 & 0.017 \\
\hline Chr2-C128T & 217 & 60 & 166 & 50 & 3.75 & 0.053 \\
\hline Chr2-D156A & 111 & 45 & 149 & 26 & 10.9 & 0.001 \\
\hline Melanopsin & 154 & 21 & 491 & 25 & 0.84 & 0.360 \\
\hline Vcomet-HRDA & 159 & 39 & 125 & 19 & 13.0 & $<0.001$ \\
\hline Vcomet-HRFY & 18 & 61 & 36 & 25 & 6.71 & 0.010 \\
\hline
\end{tabular}

(A) All reagents tested cause highly significant increases in the proportion of tadpoles showing phenotypes after exposure to the activating wavelength during early stages. (B) Activating and inactivating wavelengths should give opposite results. This was true for the PCS AAQ; however, with the caveat that the sample size for Vcomet-HRFY is too small, both LiGLuR + MAG1 and Vcomet-HRFY led to the same proportion of tadpoles with phenotypes regardless of the wavelength of illumination. (C) With the exception of $A A Q$ and $Q A Q$, which are active in the dark, leaving the embryos in the dark should inactivate the reagents. This was the case for only two of the reagents, ChR2-D156A and Vcomet-HRDA.

For tables $3-6, n$ is the sample size for the treatment at the top of the column and $\%$ is the percent of the sample that developed one or more phenotypes. For example, in table $3 \mathrm{~A}$, of $228 \mathrm{AAQ}$ treated embryos, $36 \%$ developed phenotypes when exposed to the activating wavelength, while of the 341 matched, untreated embryos, only $15 \%$ developed phenotypes; $\chi^{2}$ for the comparison was 32.6 , giving a $p<0.001$.

cells, it does not do so solely by blocking $\mathrm{K}^{+}$efflux from voltage gated $\mathrm{K}^{+}$-channels as it does in neurons.

To measure $\mathrm{V}_{\text {mem }}$ after the appearance of tomato fluorescence confirmed expression of the injected mRNA, we used the voltage reporting dye pair $\mathrm{N}$-[6-chloro-7-hydroxycoumarin-3-carbonyl] dimyristoyl phosphatidyl ethanolamine (CC2-DMPE) and bis-[1,3dibutylbarbituric acid]trimethine oxonol ( $\left.\operatorname{DiBAC}_{4}[3]\right)$; at these later stages, the cells are too small to impale. For these experiments, we examined the effects of the two Vcomets, HRDA and HRFY. These cation channels, chimeras of ChR1, VChR1 (Volvox Channelrhodopsin), and VChR2 (J. Lin, pers comm) differ from each other by two amino acids that alter the required duration of the activating light and the duration of open time. In cells expressing HRDA, we found hyperpolarization, as predicted from the function of the channels, consistent with the expressed protein being activated by the wavelengths used to excite $\operatorname{DiBAC}_{3}(4)$ (Fig. $\left.4 \mathrm{~A}-\mathrm{C}\right)$. In contrast, cells expressing HRFY were depolarized relative to non-expressing cells. This is the opposite of the predicted effect (Fig. 4 D-F). That these almost identical proteins have opposite effects on the $\mathrm{V}_{\text {mem }}$ of cells is further proof that when expressed in other cell types, and/or when observed for long periods, the effect of these channels and pumps can differ in very important ways from what is predicted and from their actions in neurons.

\section{Activating wavelengths led to phenotypes that are known to be caused by membrane potential changes}

Animals were treated with the reagents in table 1 and the effect of lighting on heterotaxia, craniofacial defects and hyperpigmentation ("phenotypes"; Fig. 5) was evaluated. We found that compared to untreated controls, all of the reagents caused phenotypes when exposed to the activating wavelength. Results were all highly significant ( $p \leq 0.001$ ), with effects ranging from $14 \%$ to $48 \%$ (Table $3 A$ ). However, when compared to inactivating wavelengths (Table 3B) or to darkness (Table $3 \mathrm{C}$ ), we found that very few of the reagents yielded the expected difference. This suggested to us that these reagents do not necessarily demonstrate the same behavior in Xenopus embryo cells as they do in neurons.

\section{Inactivating wavelengths led to phenotypes in half of the reagents tested}

We tested the effects on craniofacial development of $A A Q$, LiGluR+MAG1, QAQ, and Vcomet-HRFY when embryos were exposed to the wavelength of light reported to inactivate that reagent. AAQ-exposed and LiGLUR-expressing/MAG1-exposed embryos developed as predicted, that is, no differently from control embryos. Unexpectedly, however, QAQ injected and Vcomet-HRFY expressing embryos developed much higher proportions of tadpoles with phenotypes than did controls (Table 4). This was one of many experiments in which the effects of the treatment on embryos differed from the effects of the same treatments on neurons.

\section{The effects of leaving reagent-treated or expressing embryos in the dark were opposite predictions for half of the reagents tested}

Except for $A A Q$ and $Q A Q$, all of the reagents tested were predicted to be silent in the dark. While this was true for Arch+PMA (see below), ChR2-D156A, and the two Vcomets, the other three reagents tested, Arch alone, ChR2-C128T, and Melanopsin, all led to tadpoles with between $18 \%$ and $36 \%$ more phenotypes than untreated controls (Table 5). Moreover, the probability values for ChR2-D156A and Vcomet-HRDA were 0.017 and 0.037 respectively, i.e below the usual alpha of 0.05 , and therefore we cannot accept the null hypotheses with particularly strong confidence in those cases. Thus, we conclude that when expressed in developing Xenopus embryos, absence of light is not sufficient to inactivate these reagents, another difference between this system and neurons.

\section{Embryos left in the incubator and therefore exposed to brief periods of ambient light developed phenotypes}

In addition to raising some embryos in the dark, some embryos were raised the way we normally raise embryos, that is, inside incubators whose doors are regularly opened letting in small amounts of ambient light for a few seconds at a time. We predicted that there would be no difference between these embryos and untreated embryos as the light exposure was far below what is 
reported to be necessary to activate these reagents. We found that every treatment led to high levels of phenotypes, even under this low-light condition (Table 6). Of the two reagents that are expected to be active in the dark, only $Q A Q$ had phenotypes as predicted; $A A Q$ was the only reagent that did not cause phenotypes, thus this reagent, like the others, had the effect opposite to the prediction. Of the reagents tested both in the dark and in the incubator, only the Vcomets showed a difference between the two conditions. We consider this further evidence that in developing Xenopus cells, and unlike in neurons, these reagents may be constitutively active unless exposed to the inactivating wavelength (AAQ and LiGluR) or kept in absolute darkness.

Other controls offer further evidence of the difference between the behavior of optogenetic reagents in neurons and in Xenopus cells

In addition to examining the effects on control animals kept in darkness or minimal light exposure, we did additional controls to test our ability to predict whether optogenetic reagents would be active or not (Table 7). For example, in neurons, ChR2 requires

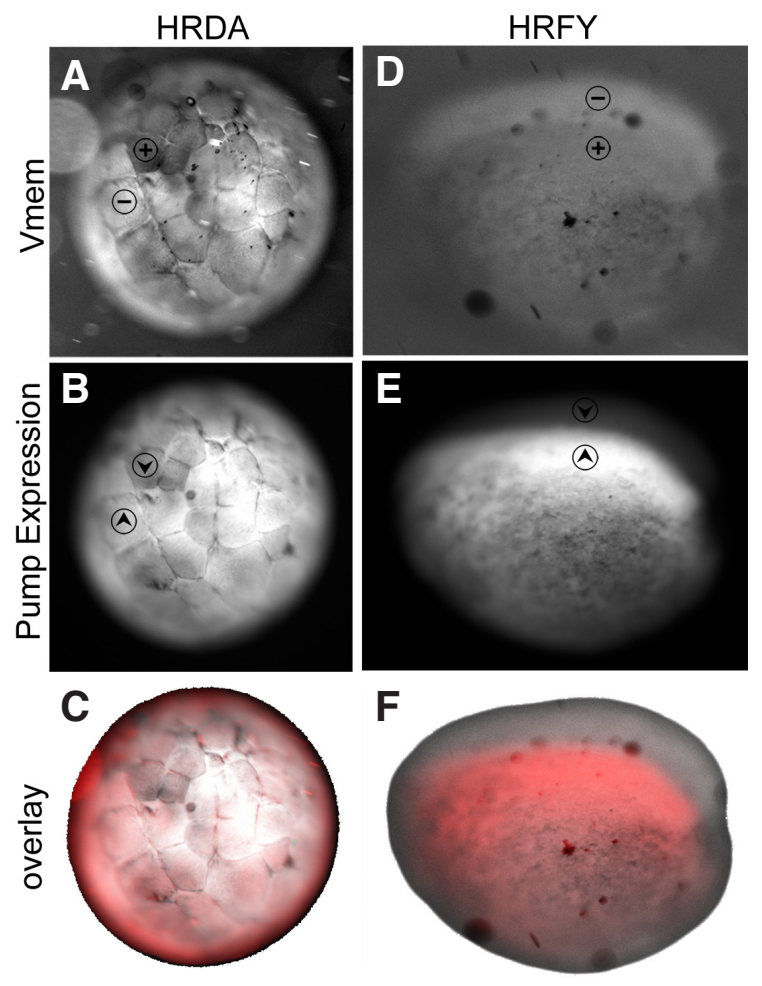

Fig. 4. Relative $\mathrm{V}_{\text {mem }}$ of Xenopus embryonic cells expressing Vcomets. We measured relative $V_{\text {mem }}$ of cells in embryos transfected with $V$ cometHRDA and Vcomet-HRFY. These reagents differ at two amino acids, and both were predicted to cause depolarization. (A-C) A \pm 128 -cell embryo expressing Vcomet-HRDA in a subset of cells. Those cells expressing higher levels (example marked with up arrow), are hyperpolarized (labeled with -) relative to those expressing less (marked with down arrow). (D-F) A stage 20 embryo; cells expressing Vcomet-HRFY (marked with up arrow) and not expressing (labeled with down arrow). In this embryo, the cells expressing the construct are depolarized (+) relative to those expressing less or none (-). The embryo in A-C is $1.2 \mathrm{~mm}$ in diameter. The embryo in $D-F$ is approximately $1.4 \mathrm{~mm}$ in length (left to right) and $1.2 \mathrm{~mm}$ tall (top to bottom). retinal to function. Xenopus is known to have endogenous retinal thus we had to determine whether additional retinal was required, either to prevent competition for the endogenous chemical or to make sure at least some was available to the ChR2. We found no difference, however, indicating that no additional retinal is needed. We got the same result when trying Vcomet-HRDA with and without retinal. We also created a version of ChR2-C128T that completely lacked the retinal binding domain. We found that even when unable to bind the light absorbing molecule, significant numbers of tadpoles developed phenotypes, even raised in the dark. We see

TABLE 4

\section{EFFECT OF INACTIVATING WAVELENGTH ON THE PROPORTION OF TADPOLES SHOWING PHENOTYPES}

\begin{tabular}{|c|c|c|c|c|c|c|}
\hline \multirow[b]{3}{*}{ mRNA or PCS } & \multicolumn{6}{|c|}{ Inactive vs NT (Predicted: NS) } \\
\hline & \multicolumn{2}{|c|}{ Inactive } & \multicolumn{2}{|c|}{ NT } & \multirow[b]{2}{*}{$\chi^{2}$} & \multirow[b]{2}{*}{$\mathbf{p}$} \\
\hline & $\mathbf{n}$ & $\%$ & $\mathbf{n}$ & $\%$ & & \\
\hline AAQ & 196 & 9 & 341 & 15 & 4.04 & 0.044 \\
\hline LiGluR + MAG1 & 54 & 17 & 317 & 14 & 0.2 & 0.693 \\
\hline QAQ & 118 & 51 & 338 & 17 & 54.2 & $<0.001$ \\
\hline Vcomet-HRFY & 78 & 37 & 365 & 13 & 26.7 & $<0.001$ \\
\hline
\end{tabular}

Half of the reagents tested caused significant numbers of tadpoles to develop phenotypes despite exposure to the wavelength that should inactivate the reagent.

TABLE 5

EFFECT OF DARKNESS ON THE PROPORTION
OF REAGENT-EXPOSED OR -EXPRESSING EMBRYOS

\begin{tabular}{|c|c|c|c|c|c|c|}
\hline \multirow[b]{3}{*}{ mRNA or PCS } & \multicolumn{6}{|c|}{ Dark vs NT (Predicted: NS) } \\
\hline & \multicolumn{2}{|c|}{ Dark } & \multicolumn{2}{|c|}{ NT } & \multirow[b]{2}{*}{$\chi^{2}$} & \multirow[b]{2}{*}{$\mathbf{p}$} \\
\hline & $\mathbf{n}$ & $\%$ & $\mathbf{n}$ & $\%$ & & \\
\hline Arch GFP & 168 & 45 & 591 & 12 & $>90.0$ & $<0.001$ \\
\hline Arch + PMA & 50 & 10 & 591 & 12 & 0.13 & 0.722 \\
\hline Chr2-C128T & 166 & 50 & 1031 & 14 & $>100$ & $<0.001$ \\
\hline Chr2-D156A & 149 & 26 & 369 & 16 & 6.3 & 0.012 \\
\hline Melanopsin & 491 & 25 & 404 & 7 & 51.9 & $<0.001$ \\
\hline Vcomet-HRDA & 125 & 19 & 442 & 12 & 4.98 & 0.026 \\
\hline Vcomet-HRFY & 36 & 25 & 365 & 13 & 4.01 & 0.045 \\
\hline
\end{tabular}

All of the reagents that we tested in the dark should have been inactive and thus shown no increase in the proportion of phenotypes. Four out of seven reagent tested led to the predicted results; however, three of the reagents caused phenotypes when exposed to light only during the one to two minutes required to move the embryos to fresh medium, which happened four times.

TABLE 6

EFFECT OF SHORT DURATION LOW ENERGY LIGHT EXPOSURE ON THE PROPORTION OF TADPOLES SHOWING PHENOTYPES

\begin{tabular}{lcccccc} 
& \multicolumn{7}{c}{ Incubator vs NT } \\
\cline { 2 - 7 } mRNA or PCS & $\mathbf{n}$ & $\%$ & $\mathbf{n}$ & $\%$ & $\chi \mathbf{2}$ & $\mathbf{p}$ \\
\hline AAQ & 303 & 21 & 341 & 15 & $>100$ & $<0.001$ \\
Arch GFP & 601 & 27 & 591 & 12 & 47 & $<0.001$ \\
Chr2-C128T & 812 & 29 & 1031 & 14 & 59.7 & $<0.001$ \\
LiGluR + MAG1 & 336 & 26 & 317 & 14 & 14.9 & $<0.001$ \\
QAQ & 197 & 31 & 338 & 17 & 15.1 & $<0.001$ \\
Vcomet-HRDA & 310 & 37 & 442 & 12 & $>70$ & $<0.001$ \\
Vcomet-HRFY & 83 & 67 & 365 & 13 & $>100$ & $<0.001$ \\
\hline
\end{tabular}

Some embryos that were not exposed to light were kept in incubators and thus, when the doors were opened, received brief exposures to ambient light that embryos kept in the dark did not receive. Most of these embryos developed a significantly higher proportion of phenotypes than untreated controls. While AAQ shows a significantly different percentage of CFAs relative to no treatment, the difference of $6 \%$ is below the designated effect size of $10 \%$, therefore we consider this a negative result. 
TABLE 7

\section{RESULTS OF OTHER CONTROL EXPERIMENTS}

\begin{tabular}{lccccccl} 
& \multicolumn{7}{c}{ other vs other } \\
\cline { 2 - 7 } mRNA or PCS & $\mathbf{n}$ & $\%$ & $\mathbf{n}$ & $\%$ & $\chi \mathbf{2}$ & $\mathbf{p}$ & comparison \\
\hline AAQ & 196 & 9 & 303 & 21 & 12.4 & $<0.001$ & Inactive vs incubator (incubator is active) \\
& 228 & 36 & 303 & 21 & 14.4 & $<0.001$ & Active vs incubator (incubator is active) \\
Arch + PMA & 50 & 10 & 168 & 45 & 2.8 & $<0.001$ & Dark; Arch+PMA vs Arch alone \\
Chr2-C128T & 139 & 37 & 217 & 60 & 18.3 & $<0.001$ & Light; with vs without retinal \\
& 166 & 50 & 64 & 44 & 0.72 & 0.395 & Dark; with vs without RB domain \\
LiGluR + MAG1 & 104 & 28 & 336 & 26 & 0.22 & 0.642 & Active vs incubator (with MAG1) \\
& 104 & 24 & 74 & 18 & 2.6 & 0.110 & Active vs + L-Glut, endogenous activator \\
Melanopsin & 84 & 26 & 491 & 25 & 0.05 & 0.824 & Dark; with vs without high [Na $]_{\circ}$ \\
QAQ & 118 & 51 & 197 & 31 & 12.3 & $<0.001$ & Active vs incubator (Incubator should be \\
& & & & & & & higher percentage) \\
Vcomet-HRDA & 30 & 53 & 159 & 39 & 2.14 & 0.143 & Active, with vs without retinal \\
Vcomet-HRFY & 36 & 25 & 78 & 37 & 1.64 & 0.200 & Dark vs inactive \\
\hline
\end{tabular}

The subjects of each comparison are indicated in the last column. As with the rest of the experiments, many of the control experiments yielded results opposite to those predicted based on published results in neurons. In this table, columns 2 and 3 describe the first treatment listed in the comparison description (column 8 ) and columns 4 and 5 describe the second.

this as strong evidence that in these cells, at least some of these reagents are light-insensitive.

Because these constructs induced phenotypes in the dark when standard amounts (nanograms) were injected, we explored whether further reduction in concentration would reduce toxicity but retain activity. We again chose ChR2-C128T to try lower dilutions. Fig. 6 shows the data for this titration experiment. We found that even lowering the dose of this mRNA to fractions of picograms did not consistently prevent the appearance of phenotypes in the absence of activating light.

\section{Manipulating external $\mathrm{Na}^{+}$concentration did not prevent melanopsin expressing embryos from developing phenotypes when raised in the dark}

We next attempted to prevent the dark phenotype seen in embryos injected with melanopsin by raising the external $\mathrm{Na}^{+}$

Fig. 5. Phenotypes caused by treatment with optogenetic reagents. These phenotypes are commonly found when bioelectrical signaling is disrupted during Xenopus development. Images are dorsal views unless otherwise indicated; $V=$ ventral, $p=$ profile. Tadpoles are anesthetized for imaging. (A-C) Views of normal tadpole with relevant structures outlined. $E$ $=$ eye $; j=j a w ; o b=$ olfactory bulb; $b=$ brain; $o c=$ otocyst $; b a=$ branchial arches. Three categories of phenotype were counted, hyperpigmentation, heterotaxia, and craniofacial abnormalities. (D) A tadpole with hyperpigmentation, which is characterized by the presence of more pigment cells, cells in normally clear regions, and greater area covered by pigment due to spreading of the cells in the plane of the skin. Spreading cannot be seen because anesthesia causes the pigment to collect in the center of the cell; however, pigmented cells can be seen covering the entire surface, including abnormal locations such as between the brain and the eye. (E) A tadpole that is heterotaxic. Heterotaxia is defined here as a reversal in the left-right patterning of one, two, or three organs, specifically the heart, gall bladder and/or gut. This example has a reversal of the loop of the heart. (F-L). Examples of the most common abnormalities of the face. (F) This profile shows a malformed anterior dorsal region. (G) This tadpole has black pigment associated with the optic nerves; the pigment appears to join the two eyes across the midline. (H) This tadpole has developed extra brain tissue. (I) The olfactory pits of this tadpole appear as one large organ. ( $\mathbf{J})$ The left eye of the tadpole is missing. (K) The jaw and branchial arches of the left side of this tadpole are small and malformed. (L) The head skeleton of this tadpole is much smaller than normal. concentration. In this case, the hypothesis was that the channels remained open in the dark, allowing cations to move out of the cells down their concentration gradients. However, raising the $\mathrm{Na}^{+}$concentration in $0.1 \mathrm{X} \mathrm{MMR}$ to $40 \mathrm{mM}$ (internal $\mathrm{Na}^{+}$concentration $=38 \mathrm{mM}$ ) did not prevent the dark phenotype (Table 7 ). We conclude that matching the direction of the $\mathrm{Na}^{+}$gradient to better approximate the conditions in a neuron was not sufficient to prevent activity of the channel in the absence of light.

\section{The Arch-dependent dark phenotype can be prevented if a constitutively-active $\mathrm{H}^{+}$-pump is co-expressed}

We hypothesized that Arch, like ChR2, which is now believed to be a leaky $\mathrm{H}^{+}$-pump (Feldbauer et al., 2009), might allow $\mathrm{H}^{+}$ influx when not activated by light. To test that hypothesis, we injected mRNA for both Arch and PMA1.2, a constitutively active $\mathrm{H}^{+}$-pump, reasoning that if Arch was importing $\mathrm{H}^{+}$, the PMA1.2mediated $\mathrm{H}^{+}$-efflux could counteract the effect and prevent the dark phenotype. Indeed, we found that PMA1.2 co-expression reduced the incidence of craniofacial phenotypes from $45 \%$ to $10 \%$, which is the background level (Tables 5,7). These data suggest that, at least in the case of Arch, the pump is not only
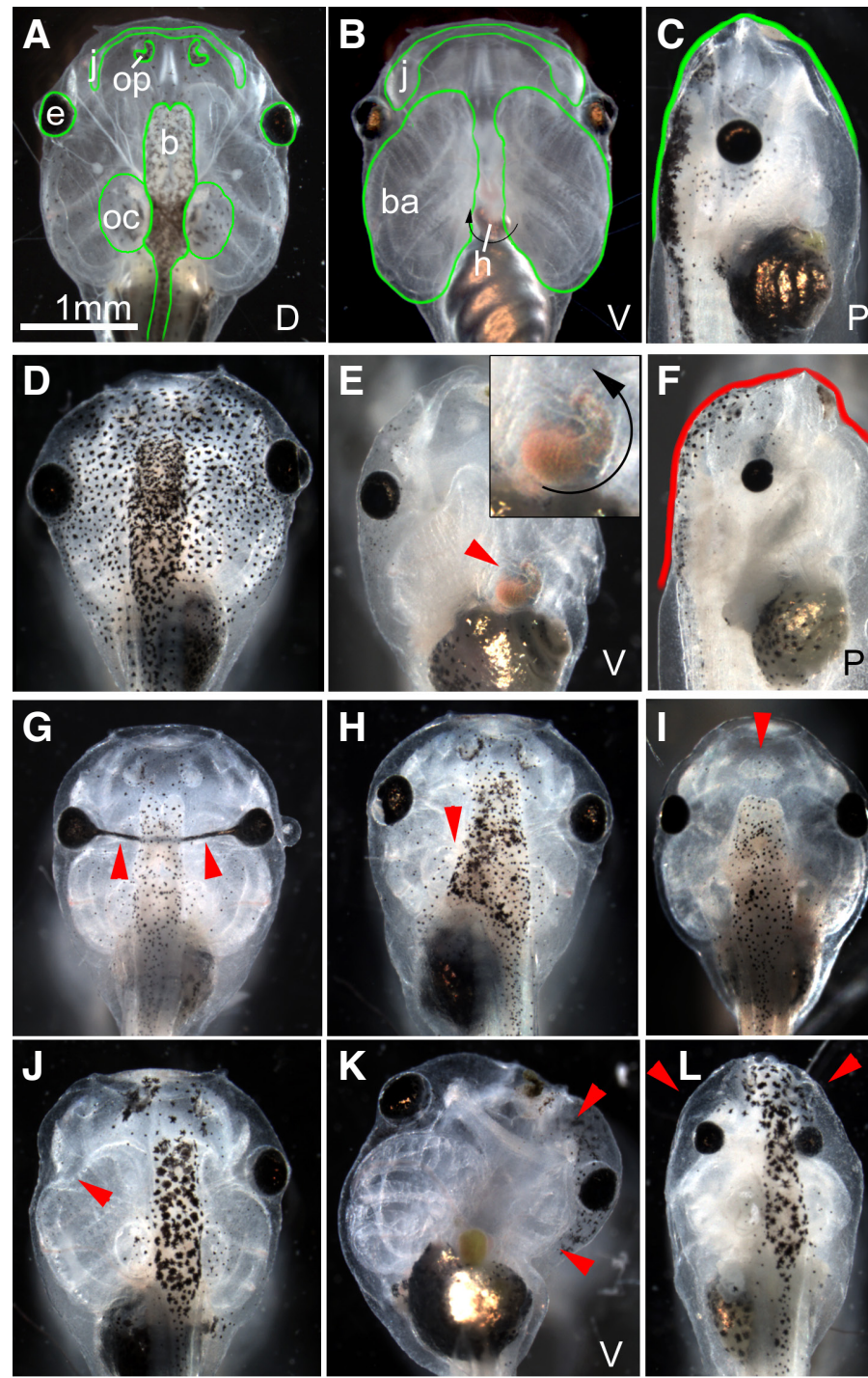


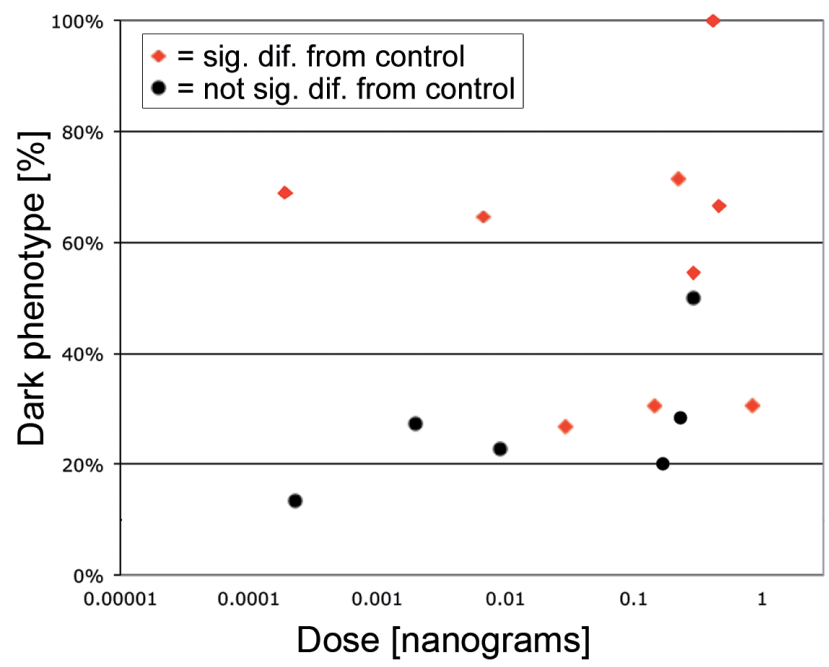

Fig. 6. Titration of ChR2-C128T. Transfection of Xenopus blastomeres by microinjection is normally accomplished by injecting nanograms of $m R N A$. To find a dose of ChR2-C128T mRNA that did not lead to phenotypes in the absence of light, serial dilution was used to lower the amount of mRNA injected. Black indicates no significant difference between treated and controls; red indicates a significant difference. Even as little as 0.5 picograms of mRNA led to significant numbers of tadpoles with phenotypes.

constitutively active, it is actively running backwards.

\section{Discussion}

We have begun to explore the utility of optogenetic reagents for use in the study of bioelectrical events during early development in Xenopus. Preliminary observations revealed that, with the exception of UV light at very early stages, the light regimens required to activate the various reagents had no effect on Xenopus development. We also found that the optogenetics reagents were expressed rapidly at the surface of these cells and at a very high rate. In this respect, embryonic, and other mitotically active cells, may prove to be more amenable to optogenetic regulation than fully differentiated cells such as neurons. For almost every optogenetic reagent tested, we observed phenotypes consistent with manipulation of resting membrane potential during early development, including hyperpigmentation, heterotaxia, and craniofacial phenotypes. We are encouraged by these results; however, much troubleshooting remains to be accomplished.

The most obvious barrier is the consistency with which we got positive results from negative controls, that is, dark phenotypes. There are some hypotheses that could at least partially explain these results. It is not impossible that in these particular cells, these exogenous channels are constitutively open or leaky due to changes in the rate of spontaneous opening. Thus, under the minimal light conditions of the incubator or under the activating (opening) wavelength, we would see phenotypes, but when the inactivating (closing) light is present, it provides the energy to close at least some of the channels. Potentially relevant in this context is the finding that ChR2, which depolarizes neurons due to a net inward current, acts as a hyperpolarizing proton-pump when expressed in other cell types (Feldbauer et al., 2009). Thus, bidirectional currents are clearly possible. Also relevant to this hypothesis is the probabilistic nature of channel opening. Even in the dark, a certain percentage of channels will be open. It is possible that a small change in cation permeability due to stochastic opening of introduced channels is amplified by the response of endogenous channels responding to a change in membrane potential. This could explain the phenotypes we observed when QAQ and Vcomet-HRDA were exposed to wavelengths that should have inactivated the reagents, but we nonetheless found high rates of phenotypes; if either of these were present in sufficiently high amounts, baseline activity could cause an effect even if the wavelength was largely inhibitory. The temperature at which Xenopus embryos develop, $14^{\circ} \mathrm{C}$ to $23^{\circ} \mathrm{C}$ could also have an effect on the stochastic behavior of the introduced ion translocators. Our success at preventing the dark phenotype associated with expression of the $\mathrm{H}^{+}$-pump Arch is consistent with the hypothesis that the pump is somehow facilitating $\mathrm{H}^{+}$influx when the activating wavelength is absent. Whether it is simply leaky, like ChR2, or if it is actively running in reverse, is yet to be determined.

Very encouraging in this context was the finding that we could counteract the effect of unwanted ion flux using a co-injected pump. Specifically, co-injection of the constitutively active yeast proton pump pma1.2erased the dark phenotype of Arch injected embryos. This illustrates a useful approach to addressing unexpected effects due to differences in reagent activity in different cell types. Indeed there are many well-characterized ion channels and pumps that could be used to modulate the net effect of optogenetic reagents. Xenopus is uniquely practical in this case because many of these ion translocators were originally characterized by expression in Xenopus oocytes.

Another important aspect of using optogenetics in new systems that is illustrated by our data relates to the vastly different external ion concentrations faced by transmembrane proteins in a mammalian neuron and transmembrane proteins in external Xenopus blastomeres that can be reached by light. The medium in which Xenopus embryos are maintained is very different from that of mammalian neurons, with a sodium concentration of less than $9.9 \mathrm{mM}$ and a chloride concentration of $11 \mathrm{mM}$. Thus, unlike in neurons, the electrochemical gradients of both sodium and chloride favor efflux. In fact, the Goldman-Hodgkin-Katz equation predicts that a change in sodium permeability will hyperpolarize, not depolarize, a Xenopus cell membrane, while a change to chloride permeability would depolarize. This idea that the differences in ionic environment could lead to dramatic changes in the activity of optogenetic reagents could explain many of our results. Indeed, it has been shown for ChR2, and two derivatives, ChEF and ChIEF (Chlamydomonas reinhardtiichannelrhodopsin 1-channelrhodopsin 2 chimeras), that changing the external cation concentration causes large shifts in the reversal potentials; for example, Lin et al., measured a change from $8 \mathrm{mV}$ to $-22 \mathrm{mV}$ for ChR2 caused by changing the external sodium concentration from $145 \mathrm{mM}$ to 5 $\mathrm{mM}$, a change comparable to the difference between extracellular fluid and 0.1X modified Marcs ringers (MMR) (Lin et al., 2009).

Despite the differential activity of these reagents in different cell types, the many positive results we obtained are important evidence that the utility of these powerful tools will extend beyond excitable cells and cells of the nervous system. What is clear from the results presented here is that it is not possible to conclude a priori that these reagents will work in the same way in different cell types. While light-induced effects of some reagents we tried matched 
predictions based on published descriptions of the mechanisms, the absence of light was not sufficient to prevent the development of phenotypes known to be caused by $\mathrm{V}_{\text {mem }}$ changes of early embryonic cells. Our evidence that, in the dark, Arch mediates influx of $\mathrm{H}^{+}$is particularly noteworthy in this respect. We therefore recommend the following to researchers attempting to use these reagents in new systems: calculation of GHK predictions of the direction of ion flow; rescue of phenotypes by co-expression of ion channels that should block activity; negative controls with wavelengths that should not affect activity; expression of optogenetic reagents in which the fluorescent protein reporter has been replaced by a tag that does not emit light.

The excellent spatial and temporal control afforded by the careful control of expression patterns and light will be a boon to countless studies in Cell and Developmental Biology wherein control of cell behavior is paramount. In particular, the use of models like Xenopus, in which developmental roles of ion currents have been well-established (Adams and Levin, 2013a, Levin, 2012, Levin and Stevenson, 2012, Pai et al., 2012, Tseng and Levin, 2012), offers exciting opportunities for the extension of the optogenetic toolkit to the control of physiological determinants of growth and form. Thus, future progress in optical control of resting potential in somatic cells in vivo is sure to open new vistas for regenerative biomedicine, bioengineering, and cancer.

\section{Materials and Methods}

\section{Xenopus laevis husbandry}

Xenopus embryos were collected and maintained according to standard protocols (Sive et al., 2000), maintained in 0.1X MMR pH 7.8, and staged according to (Nieuwkoop and Faber, 1994). At stage 45-46, after phenotypes became clearly visible, control and treated tadpoles were anesthetized with $1.5 \%$ MS-222 (tricaine) then scored for phenotypes known to be induced by either depolarization or hyperpolarization of cells, specifically hyperpigmentation, heterotaxia, and craniofacial phenotypes (Fig. 5).

\section{Constructs}

Table 1 lists the constructs discussed here. Plasmids containing optogenetic cDNAs, with and without fluorescent tags, were moved to the pCS2+ vector (Rupp et al., 1994), or its derivatives, which are designed for in vitro synthesis of capped mRNAs from linearized plasmid DNA. The expression cassette of pCS2+ contains: a 5' SP6 promoter; Xenopus beta-globin 5' untranslated sequences; polylinker 1 for insertion of the cDNA of interest; the SV40 polyadenylation signal; and finally polylinker 2 , a site to linearize the plasmid (and thus terminate transcription from the SP6 promoter). 7-methyl guanosine-capped RNA for injection was generated from linearized plasmid DNA using the SP6 mMessage Machine kit (Ambion), purified by DNAse treatment precipitated with $\mathrm{LiCl}$, washed with $70 \%$ ethanol and resuspended in RNAse-free water.

Modification of pCS2+, for some constructs, included insertion of an Ncol restriction site in polylinker 1 , to provide an optimal sequence for translation (CCACC) adjacent to an initiator methionine codon (Kozak, 1987), and modification of polylinker 2 to provide additional restriction sites for linearizing: Xmal and EcoNI. Mutagenesis was performed with oligonucleotides containing the desired mutation(s), using a QuikChange Lightning Mutagenesis Kit and QuikChange Primer Design Software from Agilent. This method was also used to mutate the putative retinol-binding site of VComet (K297S) and of ChR2 C128T (K257S). In some cases the vector was also modified for producing chimeric proteins with the fluorescent protein tomato at the carboxy terminus, replacing the original fluorescent protein tag (if one was present).

Some clones were produced by ligation of restriction-digested fragments into polylinker 1 of the vector. For insertion of cDNAs where the reading frame must be maintained (to use the Ncol site or to form a chimeric protein), the desired sequence was amplified (Platinum PFX polymerase, Life Technologies) by PCR primers (Life Technologies) that were extended with sequence matching the desired site of insertion into pCS2+. The PCR product was combined with the linearized vector by recombination of the overlapping ends by recombination, using the In-Fusion Advantage PCR Cloning Kit from Clontech. Following site directed mutagenesis the reaction mix was used to transform E.colistrain XL10-Gold, provided with the mutagenesis kit. For other constructs, E.coli strains Top10F, Stbl3, or DH5alpha (Life Technologies) were used. Correct clones were identified by sequencing (Genewiz), and the sequence was analyzed with Geneious Pro Software (Drummond AJ, 2011). Plasmid DNA was isolated using kits from Qiagen.

\section{$A A Q$ and MAG1 treatment}

$100 \mathrm{mM}$ aliquots of Acrylamide-Azobenzene-Quaternary ammonium (AAQ) in DMSO were stored desiccated at $-80^{\circ} \mathrm{C}$. Stocks were thawed and diluted to $400 \mu \mathrm{M}$ in $0.1 \mathrm{X}$ MMR immediately prior to each experiment (Fortin et al., 2008); at this concentration, DMSO has no discernable effect on development. Dishes of embryos were exposed to AAQ for 15 to 20 minutes just prior to light exposure. Diluted $A A Q$ was found to retain activity for at least 48 hours at room temperature. Maleimide-AzobenzeneGlutamate 1 (MAG1) (Volgraf et al., 2006) was stored desiccated as $30 \mathrm{mM}$ aliquots at $-20^{\circ} \mathrm{C}$. Embryos that had been injected with the light-sensitive ionotropic glutamate receptor (LiGluR) construct (see above) were soaked in $400 \mu \mathrm{M}$ MAG1 for 15 minutes immediately before exposure to light.

\section{Microinjection}

Xenopus embryos were injected with capped, synthetic mRNAs in the animal hemisphere of early cleavage stage embryos. Many years experience has shown that injection of heterologous mRNA per se does not induce phenotypes such as those reported here. For examination of craniofacial phenotypes, 1-cell embryos, or 1 blastomere of 2- or 4-cell embryos were injected. Alexa647-labeled dextran was used as a lineage tracer for all injections. Nanograms per injection were calculated from the concentration of the mRNA (determined using a NanoDrop microspectrophotometer); the minimum amount of mRNA needed to induce the phenotype was used. However, it is important to note that the intracellular fate of mRNA cannot be controlled, thus the amount of active protein produced cannot be determined in advance. Embryos were sorted based on expression levels prior to scoring of phenotypes, and only embryos with strong expression were used.

Aliquots of the photochemical switch QAQ were stored desiccated at $-20^{\circ} \mathrm{C}$ and thawed immediately prior to use. The stock was diluted to 400 $\mu \mathrm{M}$ in $18 \mathrm{M} \Omega$ water then injected into early blastomeres.

\section{Lighting}

Light was delivered in one of two ways. Circular arrays of six LEDs (HPLS-90R from Lightspeed Technologies) were used to illuminate embryos in petri dishes with most ambient light excluded. These arrays were controlled by an ELC-1000 External Laser Controller (Lightspeed Technologies), which allowed us to control the duration and frequency of the illumination. The spectra of these LEDs, measured using a USB650 Spectrometer (Ocean Optics) are given in Fig. 2. $35 \mathrm{~mm}$ or $60 \mathrm{~mm}$ plastic petri dishes of embryos rested on cooling stages that maintained the temperature between $18^{\circ}$ and $22^{\circ} \mathrm{C}$. Alternatively, embryos were placed under green light $\left(1.5 \mathrm{~mW} / \mathrm{mm}^{2}, 523 \pm 15 \mathrm{~nm}\right)$ or blue light $(0.77 \mathrm{~mW} /$ $\mathrm{mm}^{2}, 463 \pm 15 \mathrm{~nm}$ ) delivered via fiber optic cable to the inside of a lighttight box. A cooling stage also kept these embryos at or near $18^{\circ} \mathrm{C}$. To minimize phototoxicity, channel desensitization, and overheating of the medium (discovered to be a problem during preliminary experiments), the lights were blinked at frequencies appropriate to the optogenetic reagent being tested (Table 1). Embryos were left under the lights (except for daily changing of the medium and cleaning of the dishes under ambient light conditions) for up to three days. 


\section{Electrophysiology}

Predictions of the effects on $\mathrm{V}_{\text {mem }}$ and the direction of ion flux through introduced channels were based on the Goldman-Hodgkin-Katz equation using the following published values for Xenopus blastomeres and $0.1 \mathrm{X}$ MMR: $\left[\mathrm{K}^{+}\right]_{\text {out }}=0.2 \mathrm{mM},\left[\mathrm{K}^{+}\right]_{\text {in }}=51 \mathrm{mM},\left[\mathrm{Na}^{+}\right]_{\text {out }}=9.9 \mathrm{mM},\left[\mathrm{Na}^{+}\right]_{\text {in }}=38 \mathrm{mM}$, $\left[\mathrm{Cl}^{-}\right]_{\text {out }}=11.1 \mathrm{mM},\left[\mathrm{Cl}^{-}\right]_{\text {in }}=30 \mathrm{mM}$; and $\mathrm{pK}=3.72 \times 10^{-9} \mathrm{~m} / \mathrm{s}, \mathrm{pNa}=1.5 \times 10^{-8}$ $\mathrm{m} / \mathrm{s}, \mathrm{pCl}=3.9 \times 10^{-9} \mathrm{~m} / \mathrm{s}$. The online calculator at http://www.physiologyweb. com was used to calculate $\mathrm{V}_{\text {mem }}$ and the direction of ion flux. Our a priori predictions of the effects of activating various reagents were as follows: Arch, all ChR2s, LiGluR+MAG1, Melanopsin, and the Vcomets were all expected to hyperpolarize while melanopsin was expected to depolarize. $A A Q$ and $Q A Q$ block action potentials in neurons, but in embryos their effects would depend largely on the presence and activity of endogenous channels, characteristics that are unknown.

Resting membrane-voltage recordings were made using a Warner Instruments Oocyte Clamp Amplifier model OC-725C with oocyte bathclamp model 7251.I (Harvard Apparatus Company, Hampden, CT). Borosilicate microelectrodes (O.D. $1.0 \mathrm{~mm}$, I.D. $0.50 \mathrm{~mm}$ ) were filled with $2 \mathrm{M} \mathrm{KCl}$ and the embryos were bathed in $0.1 \mathrm{X}$ MMR. The amplifier was connected, via an iworx 118 analog to USB converter, to a computer running LabScribe 2 (iworx, Dover, NH). The "two cursor" mode of LabScribe was used to measure the change in potential after impaling.

Because important electrophysiological events take place in the embryo long after the cells are too small to impale, we also used voltage reporting dyes. The fluorescent bioelectricity reporter pair CC2-DMPE and $\mathrm{DiBAC}_{4}(3)$ was used to measure relative resting potential in embryos with cells too small to be impaled (Adams and Levin, 2012). Briefly, embryos were soaked in $5 \mu \mathrm{M}$ CC2-DMPE (5mM stock in DMSO was diluted 1:1000 into 0.1X MMR) for 1 to 2 hours, rinsed, then soaked in $0.95 \mu \mathrm{M} \mathrm{DiBAC}_{4}(3)(1.9 \mathrm{mM}$ stock in DMSO diluted 1:2000 in 0.1X MMR) for at least 20 minutes before imaging. Images of CC2-DMPE and $\mathrm{DiBAC}_{4}(3)$ fluorescence, as well as fluorescence of a lineage tracer (AlexaFluor 647-dextran) and expression of the fluorescent protein tomato that was conjugated to each mRNA, were collected using an Olympus BX-61 with epifluorescence optics. Images were processed to remove dark noise and uneven illumination, and the ratio of the corrected CC2-DMPE image over the corrected $\mathrm{DiBAC}_{4}(3)$ image was used to determine relative $V_{\text {mem }}$ in cells expressing vs. not expressing tomato; the higher the pixel intensity (brightness), the more polarized the cell.

\section{Statistical Analysis}

Tadpoles with one or more abnormality (hyperpigmentation, heterotaxia, and/or craniofacial phenotypes) were considered to be affected; numbers of normal and abnormal experimental embryos were compared to numbers of normal and abnormal controls using a $\chi^{2}$ test $(\alpha=0.01)$. Next, a $\chi^{2}$ test of heterogeneity was run to determine if experiments could be pooled. If justified ( $\alpha<0.01$ equivalent experiments were pooled and compared to controls by $\chi^{2}(\alpha=0.01$, effect size $=10 \%)$.

\section{Figure preparation}

Photoshop ${ }^{\mathrm{TM}}$ was used to orient, scale, and improve clarity of images; images of CC2-DMPE/DiBAC 4 (3) ratios were not manipulated for clarity. Data were neither added nor subtracted; original images are available on request. Graphs were produced with Microsoft Excel $2004^{\mathrm{TM}}$.

\section{Acknowledgements}

We are grateful to Punita Koustubhan, Erin Switzer, Claire Stevenson, and Amber Brand for Xenopus husbandry, Claire Stevenson for assistance with cloning, William Baga for administrative support, and Chris Granata for irradiance measurements. We thank Christian Bamann, John Y. Lin, Karl Deisseroth, Claire Wyart, Ehud Y. Isacoff, Ed Boyden, Ignacio Provencio, and other members of the optogenetic community for plasmids, chemicals, and many helpful suggestions. The authors gratefully acknowledge funding support from NIH [GM078484 to ML], [EY018957 to RHK], [MH088484 to $R H K$ ], and [K22 DE016633 to DSA], NSF [ CBET-0939511 to ML ] and from the Telemedicine and Advanced Technology Research Center at the U.S. Army Medical Research and Materiel Command through award [W911NF-11-2-0054 to ML].

\section{Author contributions}

DSA formulated the approach, designed and executed all experiments, interpreted data, and prepared and edited the manuscript. JL developed plasmids appropriate for use in Xenopus from reagents used in humans, interpreted data, and contributed to writing and editing the manuscript. JHK formulated the approach, interpreted data, and edited the manuscript. $M L$ formulated the approach, designed experiments, interpreted data, and edited the manuscript.

\section{Competing interests}

The authors declare no competing interests, financial or otherwise.

\section{References}

ADAMS, D., MASI, A. and LEVIN, M. (2006). Xenopus tadpole tail regeneration requires the activity of the proton pump V-ATPase, and proton pumping is sufficient to partially rescue the loss-of-function phenotype. Dev. Biol. 295: 355-356.

ADAMS, D.S. (2008). A new tool for tissue engineers: ions as regulators of morphogenesis during development and regeneration. Tissue Eng Part A 14: 1461-1468.

ADAMS, D.S. and LEVIN, M. (2012). Measuring resting membrane potential using the fluorescent voltage reporters $\operatorname{DiBAC}_{4}(3)$ and CC2-DMPE. CSH Protocols 4: 459-464.

ADAMS, D.S. and LEVIN, M. (2013a). Endogenous voltage gradients as mediators of cell-cell communication: strategies for investigating bioelectrical signals during pattern formation. Cell Tiss. Res. 352: 95-122.

ADAMS, D.S. and LEVIN, M. (2013b). Endogenous voltage gradients as mediators of cell-cell communication: strategies for investigating bioelectrical signals during pattern formation. Cell Tiss. Res. 352: 95-122.

ADAMS, D.S., MASI, A. and LEVIN, M. (2007). $\mathrm{H}^{+}$-pump-dependent changes in membrane voltage are an early mechanism necessary and sufficient to induce Xenopus tail regeneration. Development 134: 1323-1335.

ADAMS, D.S., TSENG, A.-S. and LEVIN, M. (2013). Light-activation of the Archaerhodopsin $\mathrm{H}+$-pump reverses age-dependent loss of vertebrate regeneration: sparking system-level controls in vivo. Biology Open 2:306-313.

AKERBOOM, J., CARRERAS CALDERON, N., TIAN, L., WABNIG, S., PRIGGE M., TOLO, J., GORDUS, A., ORGER, M.B., SEVERI, K.E., MACKLIN, J.J. et al., (2013). Genetically encoded calcium indicators for multi-color neural activity imaging and combination with optogenetics. Frontiers Molec. Neurosci. 6: 2.

BAMANN, C., GUETA, R., KLEINLOGEL, S., NAGEL, G. and BAMBERG, E. (2010). Structural guidance of the photocycle of channelrhodopsin-2 by an interhelical hydrogen bond. Biochem 49: 267-278.

BARRETO, G., BORGMEYER, U. and DREYER, C. (2003). The germ cell nuclear factor is required for retinoic acid signaling during Xenopus development. Mech. Dev. 120: 415-28.

BEANE, W.S., MOROKUMA, J., ADAMS, D.S. and LEVIN, M. (2011). A Chemica genetics approach reveals $\mathrm{H}, \mathrm{K}$-ATPase-mediated membrane voltage is required for planarian head regeneration. Chem. Biol. 18: 77-89.

BERNDT, A., YIZHAR, O., GUNAYDIN, L.A., HEGEMANN, P. and DEISSEROTH, K (2009). Bi-stable neural state switches. Nature Neurosci. 12: 229-34.

BERNSTEIN, J.G., GARRITY, P.A. and BOYDEN, E.S. (2012). Optogenetics and thermogenetics: technologies for controlling the activity of targeted cells within intact neural circuits. Curr. Opin. Neurobiol. 22: 61-71.

CHERNET, B.T. and LEVIN, M. (2013). Transmembrane voltage potential is an essential cellular parameter for the detection and control of tumor development in a Xenopus model. Dis Model Mech 6: 595-607.

CHERNET, B.T. and LEVIN, M. (2014). Transmembrane voltage potential of somatic cells controls oncogene-mediated tumorigenesis at long-range. Oncotarget 5 : 3287-3306.

CHOW, B.Y., HAN, X., DOBRY, A.S., QIAN, X., CHUONG, A.S., LI, M., HENNINGER, M.A., BELFORT, G.M., LIN, Y., MONAHAN, P.E. et al., (2010). High-performance genetically targetable optical neural silencing by light-driven proton pumps. Nature 463: 98-102. 
CRANE, R.F. and RUDERMAN, J.V. (2006). Using Xenopus oocyte extracts to study signal transduction. Methods Molec. Biol. 322: 435-443.

DRUMMOND AJ, A.B., BUXTON S, CHEUNG M, COOPER A, DURAN C, FIELD M, HELED J, KEARSE M, MARKOWITZS, MOIRR, STONES-HAVASS, STURROCK S, THIERER T, WILSON A. (2011). Geneious, (ed.: http://www.geneious.com)

FELDBAUER, K., ZIMMERMANN, D., PINTSCHOVIUS, V., SPITZ, J., BAMANN, C. and BAMBERG, E. (2009). Channelrhodopsin-2 is a leaky proton pump. Proc. Natl. Acad. Sci. USA 106: 12317-12322.

FENNO, L., YIZHAR, O. and DEISSEROTH, K. (2011). The development and application of optogenetics. Ann. Rev. Neurosci. 34: 389-412.

FORTIN, D.L., BANGHART, M.R., DUNN, T.W., BORGES, K., WAGENAAR, D.A. GAUDRY, Q., KARAKOSSIAN, M.H., OTIS, T.S., KRISTAN, W.B., TRAUNER, D. et al., (2008). Photochemical control of endogenous ion channels and cellular excitability. Nature Methods 5: 331-338.

HINARD, V., BELIN, D., KONIG, S., BADER, C.R. and BERNHEIM, L. (2008). Initiation of human myoblast differentiation via dephosphorylation of Kir2.1 $\mathrm{K}+$ channels at tyrosine 242. Development 135: 859-867.

KLEINLOGEL, S., TERPITZ, U., LEGRUM, B., GOKBUGET, D., BOYDEN, E.S., BAMANN, C., WOOD, P.G. and BAMBERG, E. (2011). A gene-fusion strategy for stoichiometric and co-localized expression of light-gated membrane proteins. Nature Methods 8: 1083-1088.

KNOPFEL, T., LIN, M.Z., LEVSKAYA, A., TIAN, L., LIN, J.Y. and BOYDEN, E.S. (2010). Toward the second generation of optogenetic tools. J Neurosci 30: 14998-5004.

KOIDE, T., HAYATA, T. and CHO, K.W. (2005). Xenopus as a model system to study transcriptional regulatory networks. Proc Natl Acad Sci USA 102: 4943-8.

KOIZUMI, A., TANAKA, K.F. and YAMANAKA, A. (2013). The manipulation of neural and cellular activities by ectopic expression of melanopsin. Neurosci. Res. 75: 3-5.

KOZAK, M. (1987). An analysis of 5'-noncoding sequences from 699 vertebrate messenger RNAs. Nucleic Acids Res. 15: 8125-8148.

LANGE, C., PRENNINGER, S., KNUCKLES, P., TAYLOR, V., LEVIN, M. and CALEGARI, F. (2011). The $\mathrm{H}(+)$ Vacuolar ATPase Maintains Neural Stem Cells in the Developing Mouse Cortex. Stem Cells Dev 20(5): 843-850.

LEVIN, M. (2012). Molecular bioelectricity in developmental biology: new tools and recent discoveries: control of cell behavior and pattern formation by transmembrane potential gradients. Bioessays 34: 205-17.

LEVIN, M. (2014). Endogenous bioelectrical networks store non-genetic patterning information during development and regeneration. J. Physiol. 592: 2295-2305.

LEVIN, M. and STEVENSON, C.G. (2012). Regulation of cell behavior and tissue patterning by bioelectrical signals: challenges and opportunities for biomedical engineering. Annu Rev Biomed Eng 14: 295-323.

LEVIN, M., THORLIN, T., ROBINSON, K.R., NOGI, T. and MERCOLA, M. (2002). Asymmetries in $\mathrm{H}+/ \mathrm{K}+-\mathrm{ATP}$ ase and cell membrane potentials comprise a very early step in left-right patterning. Cell 111: 77-89.

LIN, J.Y., LIN, M.Z., STEINBACH, P. and TSIEN, R.Y. (2009). Characterization of Engineered Channelrhodopsin Variants with Improved Properties and Kinetics. Biophys J. 96: 1803-1814

LOBIKIN, M., CHERNET, B., LOBO, D. and LEVIN, M. (2012). Resting potential, oncogene-induced tumorigenesis, and metastasis: the bioelectric basis of cancer in vivo. Phys Biol 9: 065002.

MCCAIG, C.D., SONG, B. and RAJNICEK, A.M. (2009). Electrical dimensions in cell science. J Cell Sci 122: 4267-76.

MIESENBOCK, G. (2011). Optogenetic control of cells and circuits. Ann. Rev. Cell Dev. Biol. 27: 731-58

MIESENBOCK, G. and KEVREKIDIS, I.G. (2005). Optical imaging and control of genetically designated neurons in functioning circuits. Annu Rev Neurosci 28: 533-563.
MOUROT, A., FEHRENTZ, T., LE FEUVRE, Y., SMITH, C.M., HEROLD, C., DALKARA D., NAGY, F., TRAUNER, D. and KRAMER, R.H. (2012). Rapid optical control of nociception with an ion-channel photoswitch. Nature Methods 9: 396-402.

NAGEL, G., SZELLAS, T., KATERIYA, S., ADEISHVILI, N., HEGEMANN, P. and BAMBERG, E. (2005). Channelrhodopsins: directly light-gated cation channels. Biochemical Soc. Trans. 33: 863-866.

NIEUWKOOP, P.D. and FABER, J. (1994). Normal table of Xenopus laevis (Daudin): a systematical and chronological survey of the development from the fertilized egg till the end of metamorphosis. Garland Pub., New York.

PAI, V.P., AW, S., SHOMRAT, T., LEMIRE, J.M. and LEVIN, M. (2012). Transmembrane voltage potential conrols embryonic eye patterning in Xenopus laevis. Development 139: 313-323.

POLOSUKHINA, A., LITT, J., TOCHITSKY, I., NEMARGUT, J., SYCHEV, Y., DE KOUCHKOVSKY, I., HUANG, T., BORGES, K., TRAUNER, D., VAN GELDER, R.N. et al., (2012). Photochemical restoration of visual responses in blind mice. Neuron 75: 271-282.

REID, B., SONG, B. and ZHAO, M. (2009). Electric currents in Xenopus tadpole tail regeneration. Dev Biol 335: 198-207.

RUPP, R.A., SNIDER, L. and WEINTRAUB, H. (1994). Xenopus embryos regulate the nuclear localization of XMyoD. Genes Dev 8: 1311-1323.

SAKAR, M.S., NEAL, D., BOUDOU, T., BOROCHIN, M.A., LI, Y., WEISS, R., KAMM R.D., CHEN, C.S. and ASADA, H.H. (2012). Formation and optogenetic control of engineered 3D skeletal muscle bioactuators. Lab Chip 12: 4976-4985.

SIVE, H., GRAINGER, R.M. and HARLAND, R. (2000). Early Development of Xenopus laevis. Cold Spring Harbor Laboratory Press, Cold Spring Harbor, New York.

SUNDELACRUZ, S., LEVIN, M. and KAPLAN, D.L. (2008). Membrane potentia controls adipogenic and osteogenic differentiation of mesenchymal stem cells. PLoS One 3: e3737.

SUNDELACRUZ, S., LEVIN, M. and KAPLAN, D.L. (2009). Role of membrane potential in the regulation of cell proliferation and differentiation. Stem Cell Rev and Rep 5: 231-246.

TSENG, A. and LEVIN, M. (2013). Cracking the bioelectric code: Probing endogenous ionic controls of pattern formation. Comm. Integ. Biol. 6: 0-1.

TSENG, A.-S. and LEVIN, M. (2012). Transducing bioelectric signals into epigenetic pathways during tadpole tail regeneration. Anatomical Rec. 295(10): 1541-1551

TSENG, A.S., BEANE, W.S., LEMIRE, J.M., MASI, A. and LEVIN, M. (2010). Induction of vertebrate regeneration by a transient sodium current. JNeurosci30: 13192-200.

VANDENBERG, L.N., MORRIE, R.D. andADAMS, D.S. (2011a). V-ATPase-dependen ectodermal voltage and $\mathrm{pH}$ regionalization are required for craniofacial morphogenesis. Dev Dyn 240: 1889-904.

VANDENBERG, L.N., MORRIE, R.D. andADAMS, D.S. (2011b). V-ATPase-dependent ectodermal voltage and $\mathrm{pH}$ regionalization are required for craniofacial morphogenesis. Dev. Dynam. 240: 1889-1904.

VOLGRAF, M., GOROSTIZA, P., NUMANO, R., KRAMER, R.H., ISACOFF, E.Y. and TRAUNER, D. (2006). Allosteric control of an ionotropic glutamate receptor with an optical switch. Nature Chem. Biol. 2: 47-52.

WARD, A., LIU, J., FENG, Z. and XU, X.Z. (2008). Light-sensitive neurons and channels mediate phototaxis in C. elegans. Nat Neurosci 11: 916-922.

WELBERG, L. (2013). Techniques: Optogenetics takes more control. Nature Rev. Neurosci. 14: 587

YANG, M. and BRACKENBURY, W.J. (2013). Membrane potential and cancer progression. Front Physiol. 4: 185

YIZHAR, O., FENNO, L.E., DAVIDSON, T.J., MOGRI, M. and DEISSEROTH, K. (2011). Optogenetics in neural systems. Neuron 71: 9-34. 


\section{Further Related Reading, published previously in the Int. J. Dev. Biol.}

Identification and characterization of Xenopus kctd15, an ectodermal gene repressed by the FGF pathway Chika Takahashi, Toshiyasu Suzuki, Eisuke Nishida and Morioh Kusakabe Int. J. Dev. Biol. (2012) 56: 393-402

\section{Contribution of mesoderm to the developing dental papilla} Michaela Rothová, Jifan Feng, Paul T. Sharpe, Renata Peterková and Abigail S. Tucker Int. J. Dev. Biol. (2011) 55: 59-64

Regulation of programmed cell death during neural induction in the chick embryo Anna Gibson, Neil Robinson, Andrea Streit, Guojun Sheng and Claudio D. Stern Int. J. Dev. Biol. (2011) 55: 33-43

\section{A change in response to Bmp signalling precedes ectodermal fate choice} Chris T. Dee, Abigail Gibson, Andrea Rengifo, Shun-Kuo Sun, Roger K. Patient and Paul J. Scotting

Int. J. Dev. Biol. (2007) 51: 79-84

Transient expression of SPARC in the dorsal axis of early Xenopus embryos: correlation with calcium-dependent adhesion and electrical coupling.

S Damjanovski, L Malaval and M J Ringuette Int. J. Dev. Biol. (1994) 38: 439 - 446.

5 yr ISI Impact Factor $(2011)=2.959$
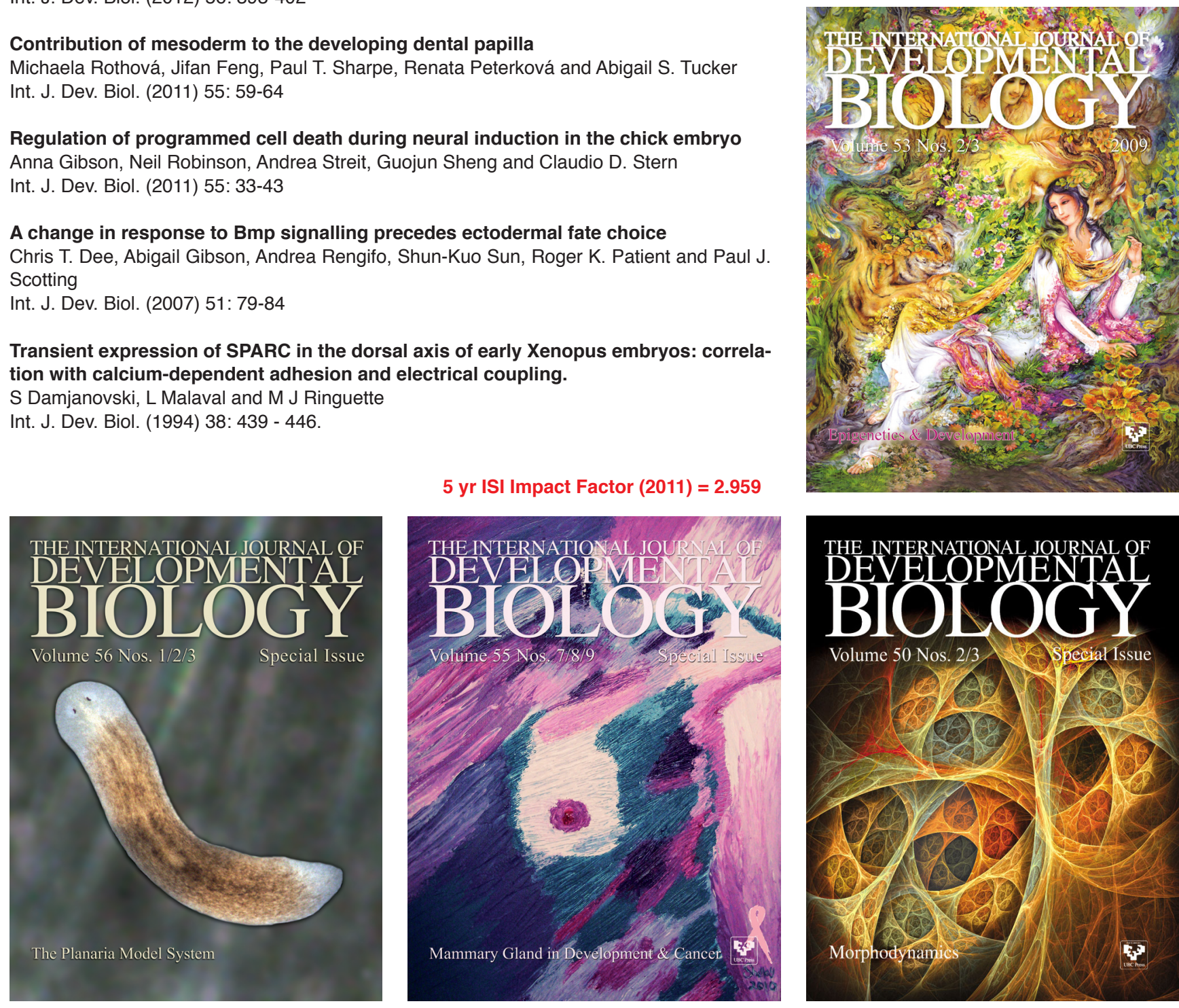